\title{
PDGF upregulates CLEC-2 to induce T regulatory cells
}

\author{
Sudhanshu Agrawal ${ }^{1}$, Sreerupa Ganguly ${ }^{1}$, Pega Hajiann ${ }^{1}$, Jia-Ning Cao ${ }^{1}$ and Anshu \\ Agrawal $^{1}$ \\ ${ }^{1}$ Division of Basic and Clinical Immunology, Department of Medicine, University of California, Irvine, CA, USA \\ Correspondence to: Anshu Agrawal, email: aagrawal@uci.edu \\ Keywords: Clec-2, dendritic cell, platelets, T regulatory cells, PDGF, podoplanin, Immunology and Microbiology Section, Immune \\ response, Immunity \\ Received: August 04, $2015 \quad$ Accepted: September 12, $2015 \quad$ Published: September 21, 2015
}

This is an open-access article distributed under the terms of the Creative Commons Attribution License, which permits unrestricted use, distribution, and reproduction in any medium, provided the original author and source are credited.

\section{ABSTRACT}

The effect of platelet derived growth factor (PDGF) on immune cells is not elucidated. Here, we demonstrate PDGF inhibited the maturation of human DCs and induced IL-10 secretion. Culture of PDGF-DCs with T cells induced the polarization of $T$ cells towards FoxP3 expressing $T$ regulatory cells that secreted IL-10. Gene expression studies revealed that PDGF induced the expression of C-type lectin like receptor member 2, (CLEC-2) receptor on DCs. Furthermore, DCs transfected with CLEC- 2 induced T regulatory cells in DC-T cell co-culture. CLEC- 2 is naturally expressed on platelets. Therefore, to confirm whether CLEC-2 is responsible for inducing the $T$ regulatory cells, $T$ cells were cultured with either CLEC-2 expressing platelets or soluble CLEC-2. Both conditions resulted in the induction of regulatory $T$ cells. The generation of $\mathrm{T}$ regulatory cells was probably due to the binding of CLEC-2 with its ligand podoplanin on $\mathrm{T}$ cells, since crosslinking of podoplanin on the $\mathrm{T}$ cells also resulted in the induction of $\mathrm{T}$ regulatory cells. These data demonstrate that PDGF upregulates the expression of CLEC- 2 on cells to induce T regulatory cells.

\section{INTRODUCTION}

Inhibition of immune response is essential to prevent uncontrolled cell activation and inflammation, both of which are detrimental to the body. Chronic inflammation is the hallmark of autoimmune diseases such as rheumatoid arthritis, multiple sclerosis etc $[1,2]$. Inflammation is controlled by regulatory $\mathrm{T}$ cells (Tregs) which are potent suppressors of cellular activation. It is well established that the number and function of Tregs is severely compromised in inflammatory and autoimmune disorders [1, 3, 4]. Immunotherapy with Tregs is also useful in transplantation where these cells can dampen the immune response and prevent graft rejection [5].

Antigen presenting cells such as dendritic cells (DCs) are capable of inducing Tregs. DCs play a crucial role in initiating immunity against invading pathogens and maintaining tolerance against self-antigens [6-8]. Encounter with pathogens activates DCs resulting in upregulation of antigen presenting and costimulatory molecules along with secretion of pro-inflammatory cytokines. In contrast, self-antigens induce secretion of anti-inflammatory cytokines [6-8]. Absence of costimulation and secretion of anti-inflammatory cytokines results in DCs which induce T cell tolerance. Such DCs are known as tolerogenic DCs (Tol DC). Tol DCs induce T cell tolerance by generation of Ag-specific, anergic CD4 ${ }^{+}$ $\mathrm{T}$ cells and the peripheral induction of $\mathrm{CD}^{+} \mathrm{CD} 25^{+} \mathrm{Foxp} 3^{+}$ T regulatory cells (Tregs) [7, 9].

This has led to the development of a number of in vitro methods for the generation of Tol DCs. Both genetic and pharmacological inhibitors have been investigated. Modification of DC in vitro with immunosuppressive cytokines such as IL-10, transforming growth factor- $\beta$ (TGF-beta) or molecules such as indoleamine dioxygenase [IDO], is a relatively simple way to generate TolDC [10, 11]. Similarly, in vitro treatment of DCs by molecules that prevent their activation also generates Tol DCs. Examples include drugs that inhibit nuclear factor $\kappa \mathrm{B}(\mathrm{NF} \kappa \mathrm{B})$ signaling-for example, the BAY 11-7085 compound, dexamethasone and vitamin $\mathrm{D}_{3}[12,13]$.

Platelets release several factors such as, TGF- $\beta$, vascular endothelial growth factor (VEGF), and plateletderived growth factor (PDGF) on aggregation [14-16]. PDGF along with VEGF is considered a key driver of angiogenesis [17]. PDGF and its receptor, platelet-derived growth factor receptor- $\beta$ (PDGFR- $\beta$ ), are essential to pericyte recruitment, a critical component of maturing 
blood vessels $[17,18]$. In addition to their effects on vasculature, these factors also affect the immune cells since the receptors for these factors are also expressed on DCs and T cells [19]. Both TGF- $\beta$ and VEGF have been demonstrated to suppress DC activation [20,21]; however, the effect of PDGF on DCs has not been investigated.

Here we report that PDGF has a profound effect on human DC functions and induces $\mathrm{T}$ regulatory cells via the expression of $\mathrm{C}$-type lectin like receptor member 2 (CLEC-2).

\section{RESULTS}

\section{PDGF induces IL-10 in DCs}

PDGF exists as 3 different isoforms in humans, PDGF-AA, PDGF-BB and PDGF-AB with PDGF-AB being the most abundant isoform $[17,22]$. DCs were cultured with $\mathrm{PDGF}-\mathrm{AB}$ at concentrations ranging from
A

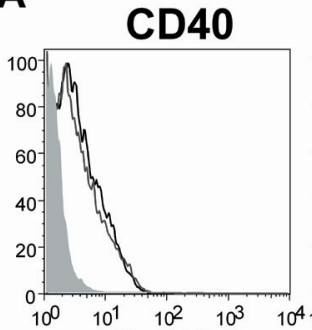
HLADR

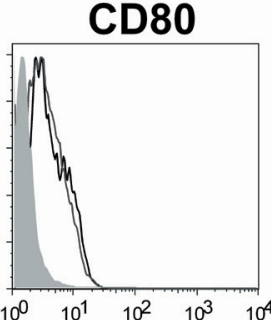
CD83

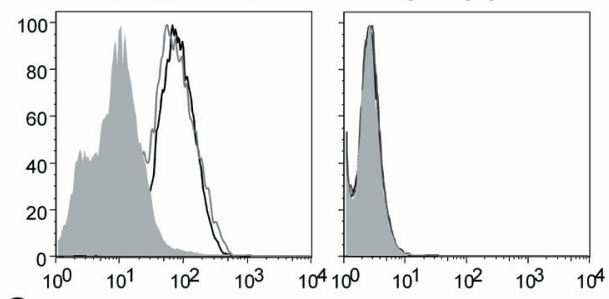

C

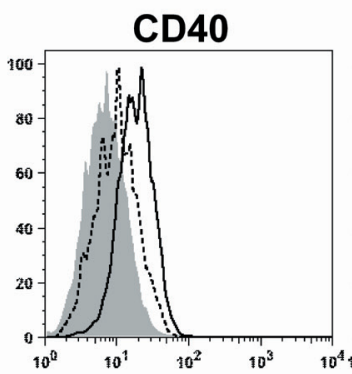

HLADR

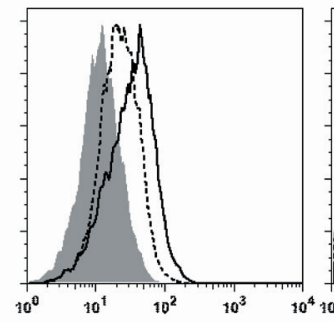

CD80

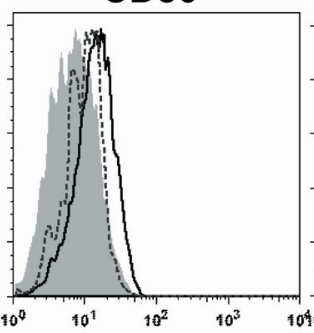

CD83

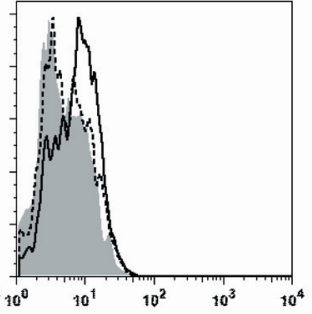

B
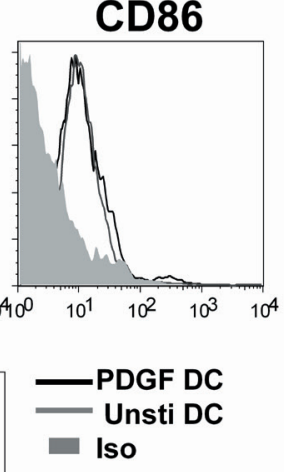

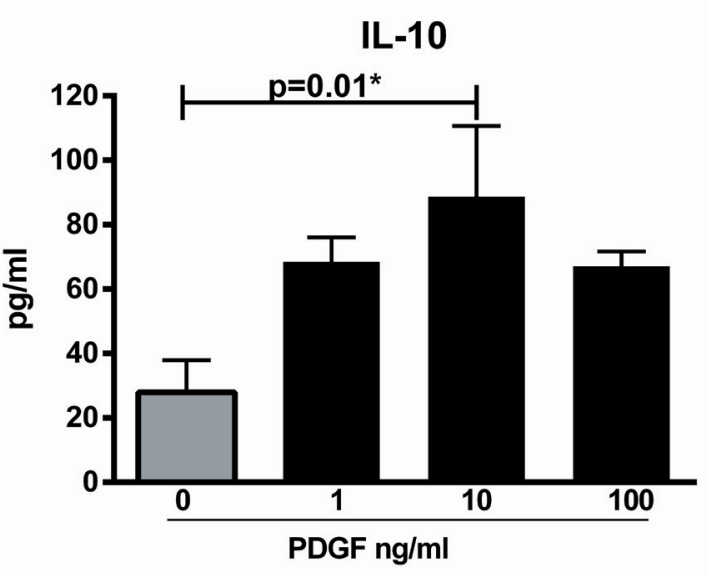

D
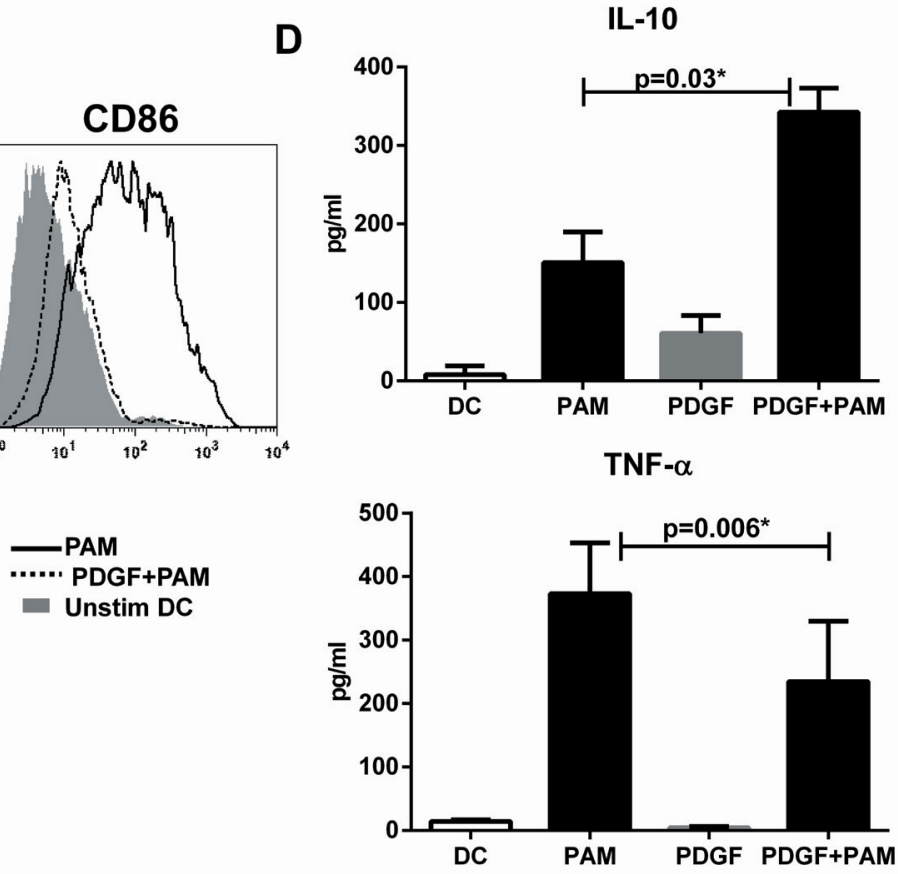

Figure 1: PDGF induces IL-10 in DCs. DCs were cultured with PDGF AB at (1-100ng/ml) for 48h. A. Histograms depict the expression of costimulatory and antigen presenting molecules on PDGF stimulated DC (PDGF-DC) and unstimulated DC. Data is representative of 6 such experiments. B. Bar graph depicts the level of IL-10 secreted by PDGF-DC and unstimulated DC. DCs were exposed to PDGF for $24 \mathrm{~h}$ and subsequently stimulated overnight with PAM. C. Histograms depict the expression of costimulatory and antigen presenting molecules on PAM stimulated DC (PAM), PDGF exposed +PAM-stimulated DCs (PDGF+PAM) and unstimulated DC. Data is representative of 6 such experiments. B. Bar graph depicts the level of IL-10 secreted by PDGF-DC and unstimulated DC. Data is mean $+/$ - S.E. of 4 different subjects. 
$1-100 \mathrm{ng} / \mathrm{ml}$ for $48 \mathrm{~h}$. Addition of PDGF did not lead to change in expression of antigen presenting (HLADR) and maturation makers (CD40, CD80, CD86, CD83) on DCs (Figure 1A). Data presented is with PDGF at 10ng/ $\mathrm{ml}$ since other concentrations of PDGF were comparable.

The cytokine secretion by DCs was determined using multiplex bead assay. PDGF stimulated DC (PDGFDC) secreted significantly higher $(p<0.05)$ levels of IL-10 compared to unstimulated DCs (Figure 1B). The secretion followed a bell shaped curve with maximum secretion being observed at a concentration of PDGF $10 \mathrm{ng} / \mathrm{ml}$. The levels of TNF- $\alpha$, CXCL-8, IL-6, MCP-1, and CXCL-10 were comparable to unstimulated DCs (data not shown). These data suggest that DCs stimulated with PDGF may be immunosuppressive.

To further confirm that indeed PDGF is immunosuppressive, DCs were treated with PDGF and subsequently stimulated with TLR-2 ligand, PAM-3 Cysteine (PAM). As is evident from figure $1 \mathrm{C}$, exposure to PDGF inhibited the upregulation of DC maturation markers by PAM. Moreover, the secretion of proinflammatory cytokine, TNF- $\alpha$ was significantly reduced $(p<0.05)$ while the secretion of IL-10 was significantly increased $(p<0.05)$ in PDGF exposed, PAM-stimulated DCs (PDGF-PAM) (Figure 1D). Together, these data suggest that exposure to PDGF renders the DCs tolerogenic.

\section{PDGF stimulated DCs induce T regulatory cells}

We then investigated whether increased IL-10 secretion by DCs resulted in polarization of T helper cell response towards a $\mathrm{T}$ regulatory phenotype. PDGF-DC and unstimulated DCs were cultured with purified, CFSE labeled naïve CD4 $\mathrm{T}$ cells for six days. IFN- $\gamma$ secretion from PDGF-DC-T co-culture was significantly $(p<$ 0.05 ) lower and IL-10 secretion was significantly ( $p<$ $0.05)$ higher than that of unstimulated DC-T co-culture (Figure 2A \& 2B). The level of TGF- $\beta$ in the supernatant was below the limit of detection (data not shown). IL4, IL-5 levels were also comparable (data not shown). Similar results were obtained with $\mathrm{T}$ cells cultured with PDGF-treated PAM stimulated DCs (Figure 2C \& 2D). Staining of $\mathrm{T}$ cells with FoxP3, signature regulatory $\mathrm{T}$ cell transcription factor revealed that PDGF stimulated DC significantly enhanced the differentiation of $\mathrm{T}$ helper cells towards Tregs verses the unstimulated DC (Figure $2 \mathrm{E} \& 2 \mathrm{~F})$. The proliferation of CD4 cells was also significantly $(p<0.05)$ reduced after culture with PDGFDCs as compared to unstimulated DCs (Figure 2G). PDGF stimulated DC thus bias the $\mathrm{T}$ cell response towards a regulatory phenotype.

\section{PDGF upregulates the expression of C-type lectin receptor, CLEC-2 on DCs}

Expression of a variety of inhibitory costimulatory molecules on DCs can induce T regulatory cells [12]. Here we determined the expression of Programmed Cell death Ligand 1 (PDL-1), PDL-2 (B7DC) and B7Rh on PDGFDCs using specific antibodies. There was no significant difference in the expression of these molecules between PDGF stimulated DC and controls (Figure 3A). Since expression of numerous other inhibitory costimulatory molecules as well as other molecules such as IDO in DCs can induce the differentiation of T regulatory cells, we performed affymetrix gene expression microarray to determine the difference between PDGF stimulated DC and unstimulated DC. The gene expression pattern of both groups was highly homologous and only 12 (all upregulated) genes were significantly different between the two groups (Table 1). None of the genes were known to induce $\mathrm{T}$ regulatory cells. One of gene which was significantly upregulated on PDGF stimulated DC was CLEC-2 which is C-type lectin receptor expressed primarily on platelets [23]. Since CLEC-2 was the only gene which was expressed on cell surface and may possibly interact with $\mathrm{T}$ cells to generate Tregs we focused our attention on this gene. The expression of CLEC-2 receptor was compared between PDGF-DC and unstimulated DC using CLEC-2 specific antibodies (Figure 3B). The expression was significantly higher $(p<$ $0.05)$ on PDGF-DCs. These data demonstrate that PDGF induces the expression of CLEC-2 on DCs.

\section{CLEC-2 expression on DC induces $\mathrm{T}$ regulatory cells}

To confirm that expression of CLEC-2 was responsible for regulatory nature of PDGF-DC, unstimulated DCs were transfected with CLEC-2 plasmid (gift from Dr. Steve Watson, University of Birmingham, U.K.)[24] using magnetofection. This resulted in significant expression of CLEC-2 on DCs $48 \mathrm{~h}$ after transfection (Figure 4A). CLEC-2 expressing DCs were collected and cultured with $\mathrm{T}$ cells as described in Figure 2. Determination of cytokines in the supernatant revealed that while the IFN- $\gamma$ levels were comparable (Figure 4B), IL-10 secretion was significantly increased in CLEC-2 DC-T co culture (Figure 4C). Moreover, culture of CLEC2 transfected DCs with $\mathrm{T}$ cells generated significantly increased percent of Treg cells as compared to mock transfected DCs (Figure 4D). Thus CLEC-2 expression in DCs bestows the ability to induce the differentiation of Tregs. 


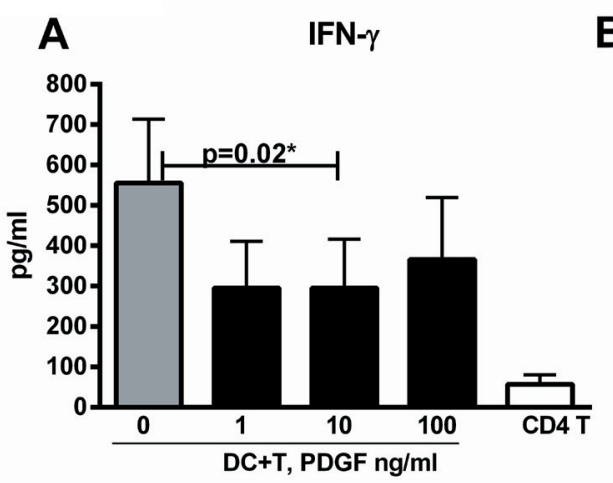

B IL-10

C

IL-10

D
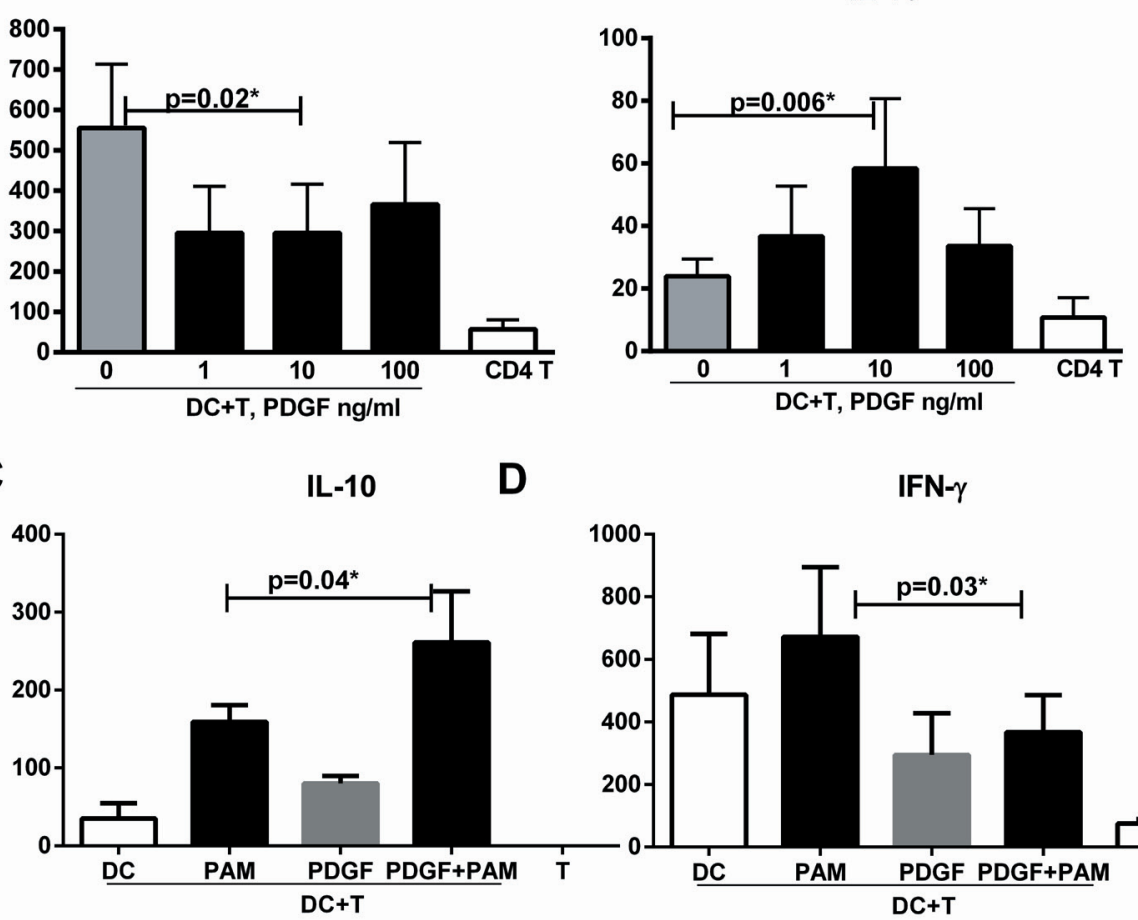

IFN- $\gamma$

E
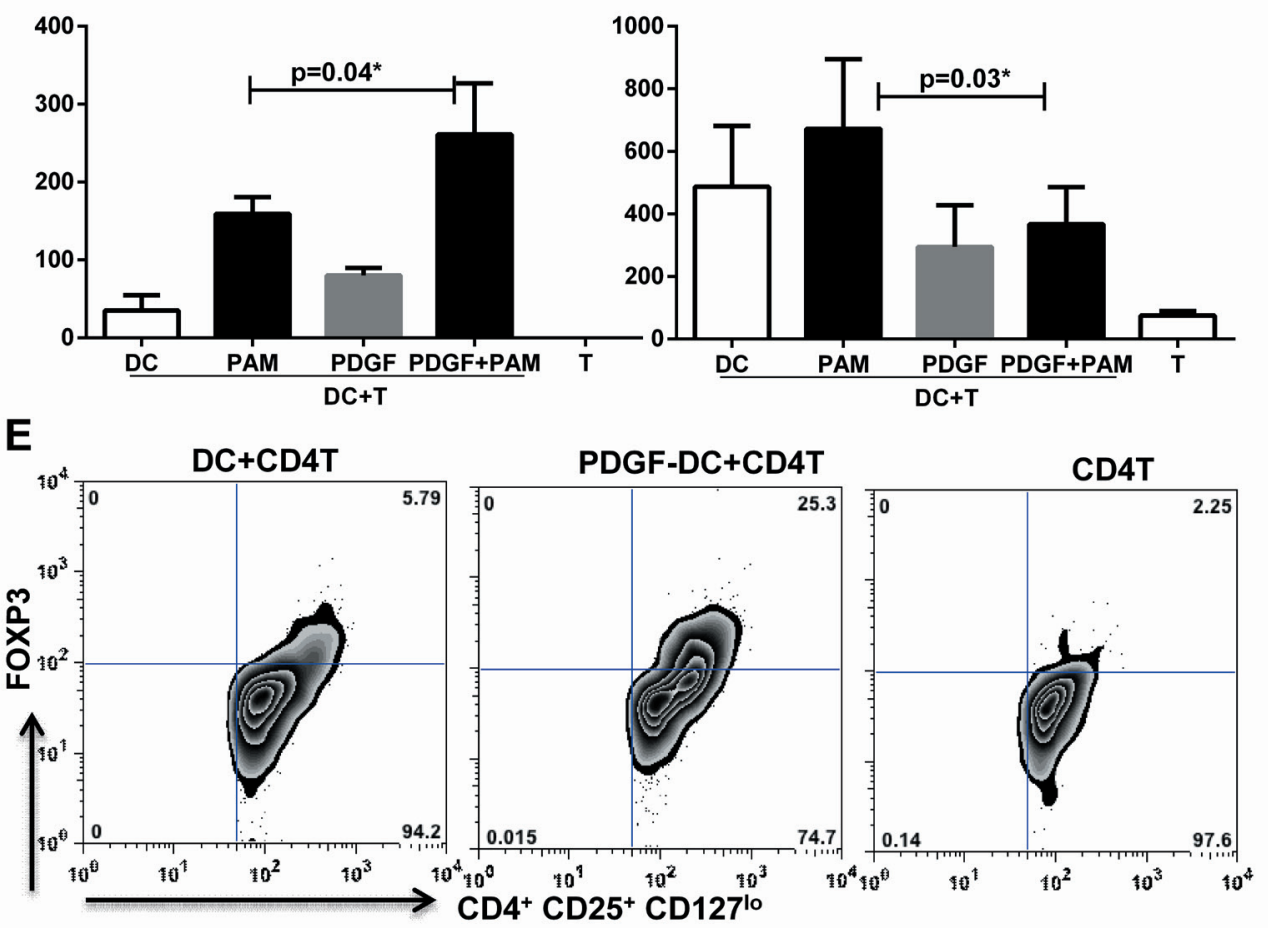

$\mathbf{F}$

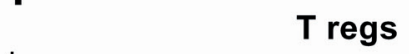

G
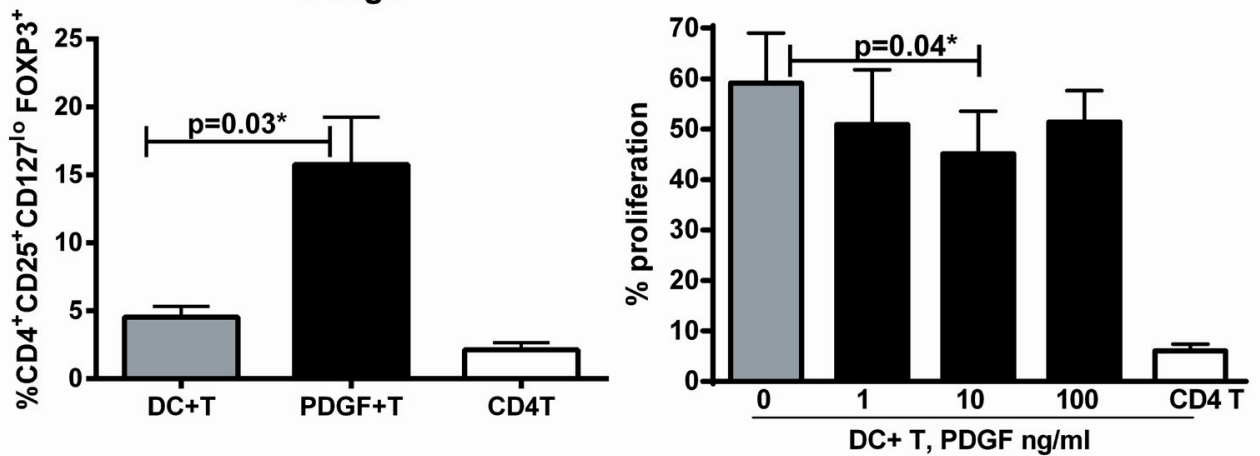

Figure 2: PDGF-DC induces T regulatory cells. PDGF-DC and unstimulated DC were cultured with CD4T cells for 5 days. Bar graphs depict the levels of A. IL-10 and B. IFN- $\gamma$ secreted by T cells. Data is mean +/- S.E. of 5 different subjects. PDGF-DC, PAMstimulated DCs, PDGF-PAM DCs and unstimulated DC were cultured with CD4T cells for 5 days. Bar graphs depict the levels of C. IL-10 and D. IFN- $\gamma$ secreted by T cells. Data is mean + /- S.E. of 4 different subjects. E. Zebra plot depicts the percentage of FoxP3 ${ }^{+}$cells in gated $\mathrm{CD} 4{ }^{+} \mathrm{CD} 25^{+} \mathrm{CD} 127^{10}$ cells in DC-T cell coculture. Figure is representative of 4 such experiments. F. Bar graph depicts the mean $+/-$ S.E. of the same. E. Bar graph depicts the percent of T cell proliferation as measured by CFSE dye dilution. Data is mean +/- S.E. of 6 different subjects. 
Table 1: A list of 12 genes with expression changes in DCs activated with PDGF and meeting the criteria of $p<0.05$ (student's t-test), FDR $<5 \%$, and fold change $\geq \mathbf{1 . 2 5}$.

\begin{tabular}{|l|l|l|l|l|l|}
\hline Gene Identifier & Other ID & Gene ID & Ratio & Direction & $\boldsymbol{p}$-value \\
\hline NM_053039 & 8095404 & UGT2B28 & 1.39 & Up & 0.023 \\
\hline NM_005267 & 7904927 & GJA8 & 1.37 & Up & 0.044 \\
\hline NM_021176 & 8046116 & G6PC2 & 1.33 & Up & 0.004 \\
\hline NM_001130711 & 7961091 & CLEC2A & 1.32 & Up & 0.028 \\
\hline NM_001104 & 7941662 & ACTN3 & 1.27 & Up & 0.037 \\
\hline NM_175057 & 8122127 & TAAR9 & 1.26 & Up & 0.010 \\
\hline NM_181538 & 8141371 & GJC3 & 1.26 & Up & 0.013 \\
\hline NM_003081 & 8060963 & SNAP25 & 1.26 & Up & 0.004 \\
\hline NM_001753 & 8135594 & CAV1 & 1.25 & Up & 0.044 \\
\hline NM_001105578 & 8034583 & SYCE2 & 1.25 & Up & 0.010 \\
\hline NM_001003395 & 8121838 & TPD52L1 & 1.25 & Up & 0.001 \\
\hline
\end{tabular}
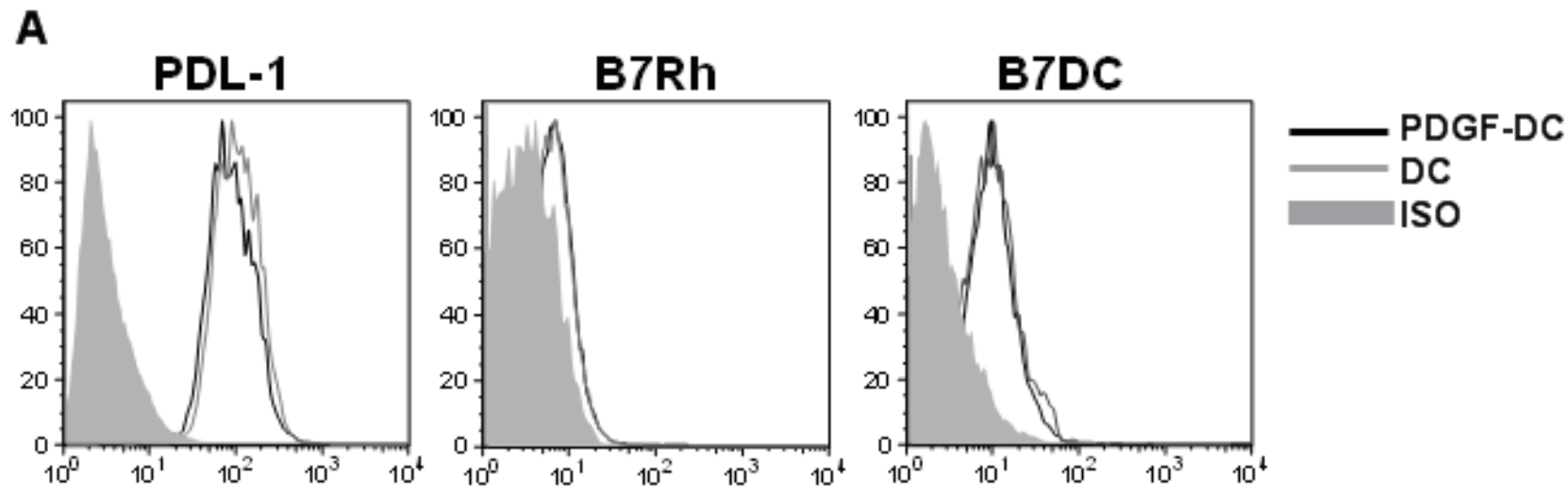

B
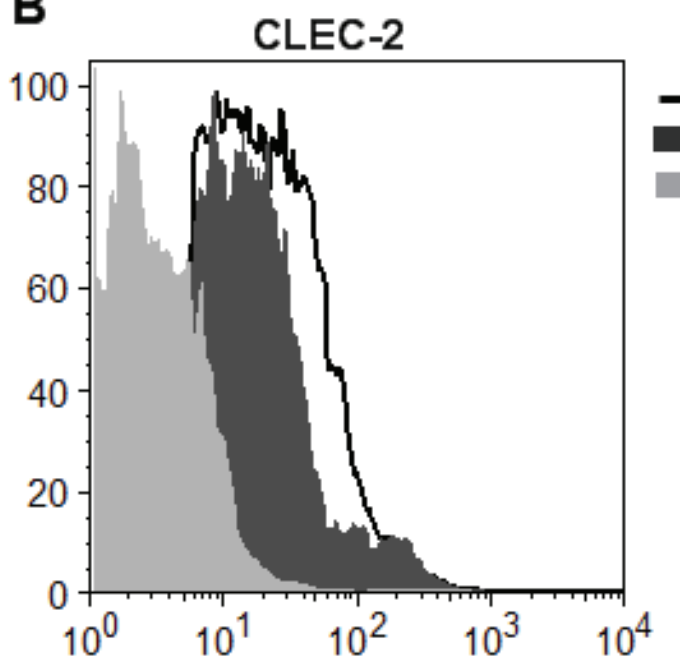

Figure 3: PDGF upregulates the expression of C-type lectin receptor, CLEC-2 on DCs. DCs were cultured with PDGF AB at $(1-100 \mathrm{ng} / \mathrm{ml})$ for $48 \mathrm{~h}$. Histograms depict- A. the expression of inhibitory costimulatory molecules on DCs. B. The expression of CLEC-2 on DCs. Data is representative of 6 such experiments. 


\section{CLEC-2 expression on platelets also induces $T$ regulatory cells}

Next we determined if CLEC-2 expression on APCs such as DCs is required for inducing $\mathrm{T}$ regs or any cell expressing CLEC-2 is capable of inducing the T regs. Platelets in the blood naturally express CLEC-2 to interact with endothelium $[23,25]$. Therefore, we purified platelets from the blood and confirmed the expression of CLEC2 on purified platelets (Figure 5A). The purified platelets were cultured with syngeneic unactivated $\mathrm{T}$ cells and the induction of $\mathrm{T}$ regs was determined. As shown in Figure $5 \mathrm{~B}$, culture of platelets with $\mathrm{T}$ cells resulted in significant increase $(p<0.05)$ in $\mathrm{CD} 4{ }^{+} \mathrm{CD} 25^{+} \mathrm{CD} 127^{\text {lo }} \mathrm{FoxP}^{+}$, Tregs (Figure 5B \& 5C). This increase was proportional to the number of platelets. Platelet to T cell ratio of 2:1 was found to be optimal since the increasing the ratio to 5:1 did not result in significant increase over 2:1. T cells cultured with Platelets also secreted high levels of TGF- $\beta$, IL-10 compared to T cell cultured alone (Figure 5D). The secretion of IFN- $\gamma$ was concomitantly reduced. Culture of platelet alone did not result in detectable level of these cytokines (data not shown).

Next we determined the effect of platelets on antiCD3 and anti-CD28 bead activated T cells. Treg induction (Figure 5E) and cytokine secretion (Figure 5F) results were similar to that obtained with unactivated T cells. In addition, we also measured proliferation. The proliferation index of T cells was also significantly reduced $(p<0.05)$ in the presence of platelets (Figure 5G).

Collectively, these results suggest that CLEC-2 expressing cells stimulate $\mathrm{T}$ cells to induce a $\mathrm{T}$ regulatory phenotype.
A

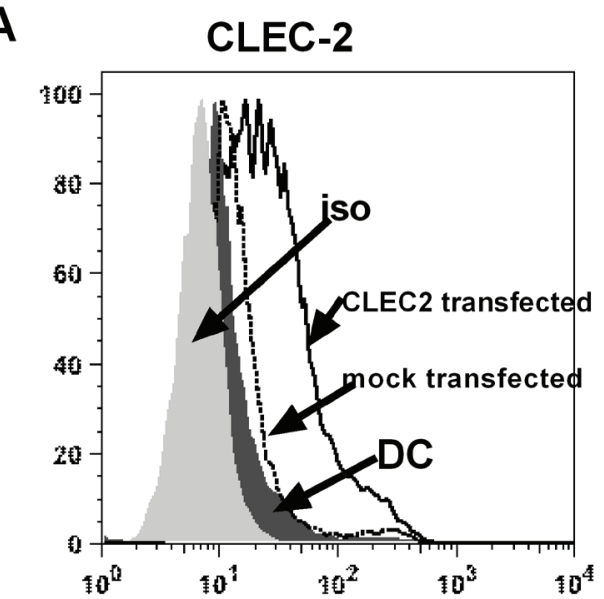

C

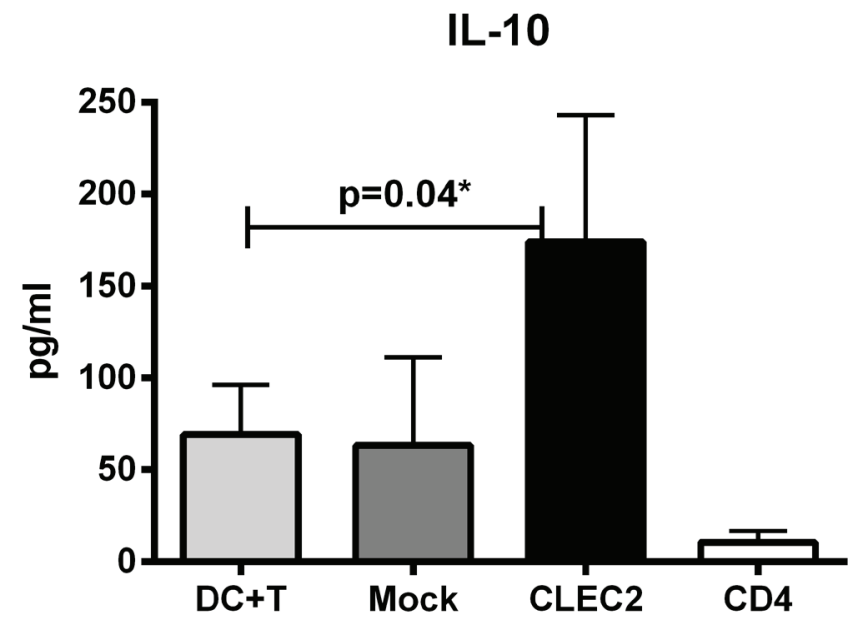

D
B

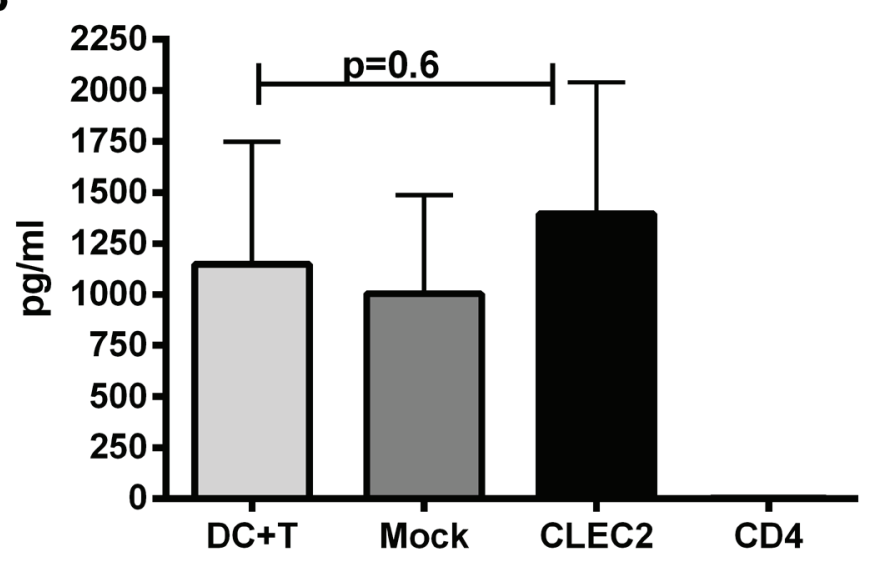

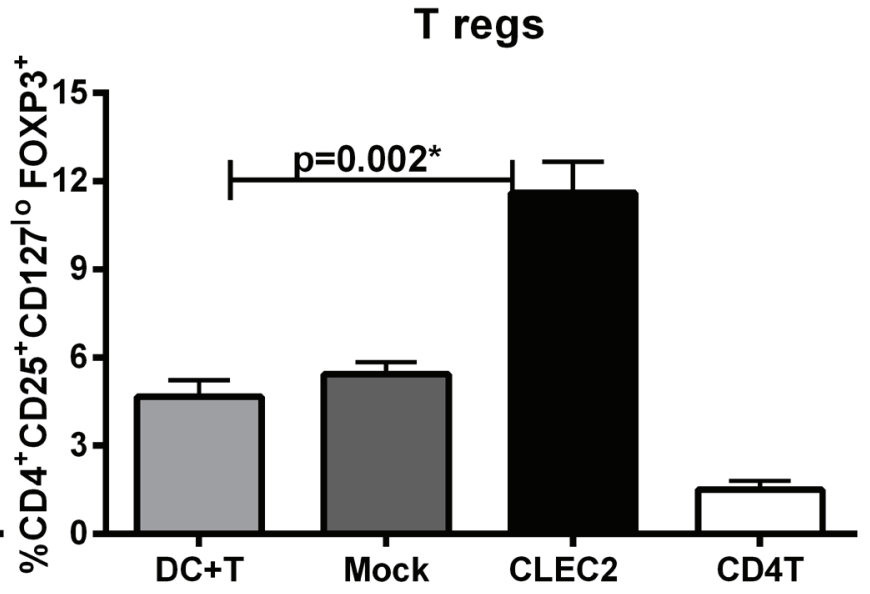

Figure 4: CLEC-2 expression on DC induces T regulatory cells. DCs were transfected with CLEC-2 and subsequently cultured with T cells for 5 days. A. Histograms depict the expression of CLEC-2 on DCs $48 \mathrm{~h}$ after transfection. Mock is mock transfected DC. Data is representative of 5 such experiments. Bar diagram depicts the levels of B. IFN- $\gamma$ and C. IL-10 and secreted by T cells. Data is mean $+/-$ S.E. of 6 different subjects. C. Bar graph depicts depicts the percentage of FoxP $3^{+}$cells in gated CD $4^{+} \mathrm{CD} 25^{+} \mathrm{CD} 127^{\mathrm{lo}}$ cells in DC-T cell coculture. Data is mean $+/-$ S.E. of 6 subjects. 


\section{Addition of soluble CLEC-2 protein/ podoplanin antibody to $T$ cells also induces $T$ regulatory cells}

The two known ligands for CLEC-2 are the Podoplanin and snake venom rhodotoxin [23, 26]. Recent studies have demonstrated that $\mathrm{T}$ cells express Podoplanin in mice [27]. We confirmed the expression of Podoplanin on human CD4 T cells (Figure 6A). Podoplanin was expressed on naïve, central and effector memory subsets with highest expression on effector memory subset. Next, we determined whether purified, soluble CLEC-2 protein can bind to $\mathrm{T}$ cells. Indeed, there was significant binding of CLEC-2 on T cells (Figure 6B). Since CLEC-2 expression on two very different cell types, DCs and platelets was leading to the induction of Tregs, we investigated if the protein itself was enough to generate Tregs or it requires accessory signals from the cells. Purified T cells were cultured with recombinant CLEC-2 and induction of Tregs was determined. Addition of CLEC-2 alone resulted in increase in Tregs (Figure 6C). The production of TGF- $\beta$ and IL-10 was also significantly higher $(p<$
0.05) in the T cells cultured with CLEC-2 protein (Figure $6 \mathrm{D})$. IFN- $\gamma$ secretion was very low; despite this, it was reduced in CLEC-2 treated T cells (Figure 6D). These data demonstrate that CLEC-2 protein by itself is sufficient to induce Tregs.

Since CLEC-2 most likely interacted with podoplanin on $\mathrm{T}$ cells, we determined whether crosslinking of podoplanin on $\mathrm{T}$ cells using specific antibody also resulted in induction of T regs. Indeed, as shown in Figure $6 \mathrm{E}$, ligation of podoplanin on unactivated $\mathrm{T}$ cells resulted in significantly increased $(p<0.05)$ induction of T regs compared to $\mathrm{T}$ cells crosslinked with isotype specific antibody. Similar to CLEC-2, podoplanin antibody treatment of $\mathrm{T}$ cells also resulted in significantly increased secretion of TGF- $\beta$ and IL-10 with a concomitant reduction IFN- $\gamma$ Figure 6F).

Taken together, these results demonstrate that CLEC-2 protein binds with podoplanin on $\mathrm{T}$ cells to induce $\mathrm{T}$ reg cells.

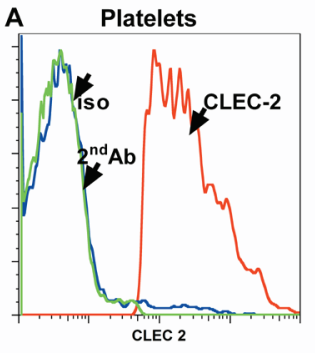

B
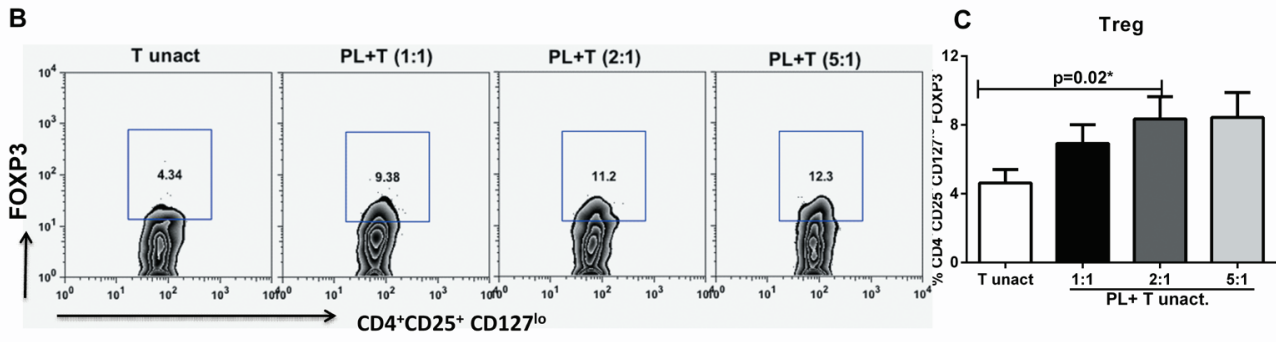

D
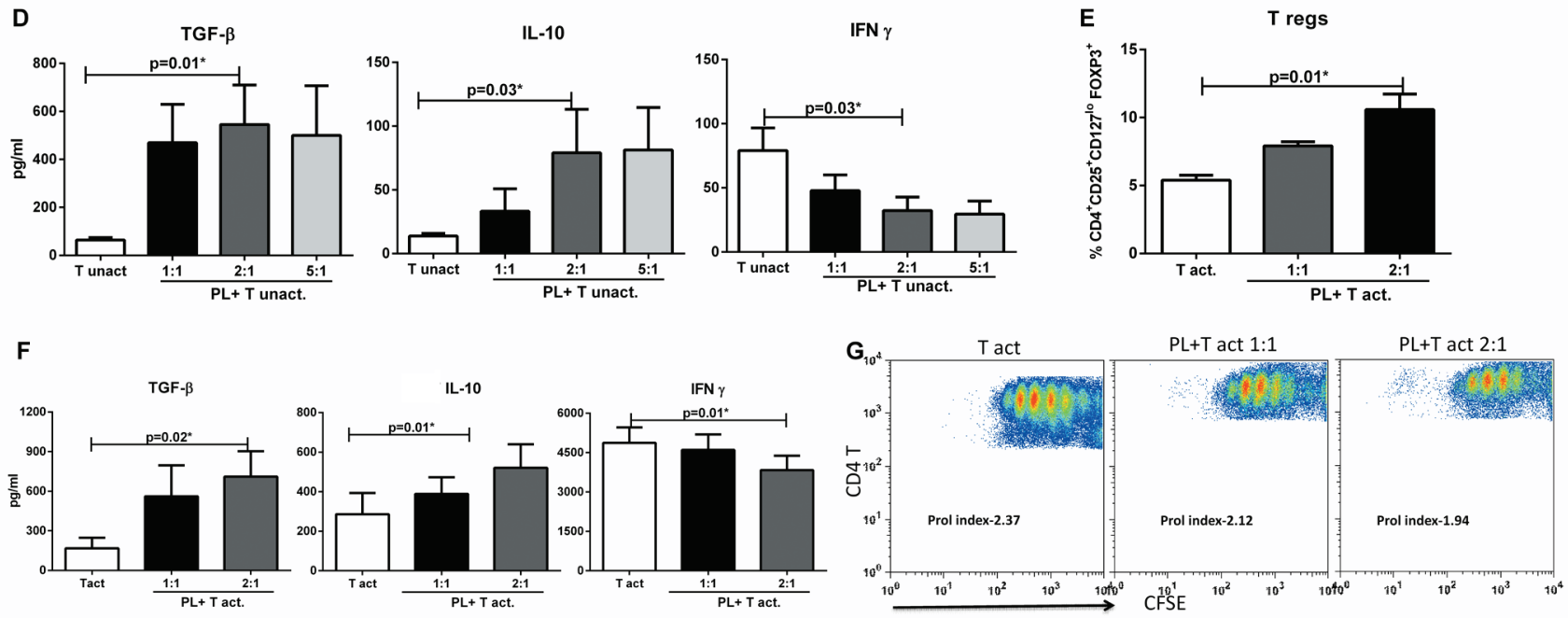

Figure 5: CLEC-2 expression on platelets induces T regulatory cells. Platelets were cultured with $\mathrm{T}$ cells for $96 \mathrm{~h}$. A. Histogram depicts the expression of CLEC-2 on freshly isolated platelets. B. Zebra plot depicts the percentage of FoxP3 $3^{+}$cells in gated $\mathrm{CD} 4{ }^{+} \mathrm{CD} 25^{+} \mathrm{CD} 127^{10} \mathrm{FoxP} 3^{+}$cells in PL-CD4+T (unactivated) cell coculture. Figure is representative of 5 such experiments. C. Bar graph depicts the mean $+/$ - S.E. of the same. D. Bar graphs depict the production of TGF- $\beta$, IL-10 and IFN- $\gamma$ in the co-culture. Data is mean $+/-$ S.E. of 5 different subjects. E. Bar graph depicts the percentage of FoxP3 $3^{+}$cells in gated $\mathrm{CD} 4{ }^{+} \mathrm{CD} 25^{+} \mathrm{CD} 127^{10} \mathrm{FoxP} 3^{+}$cells in PL-T (anti CD3+anti- CD28 activated) cell coculture. F. Bar graphs depict the production of TGF- $\beta$, IL-10 and IFN- $\gamma$ in the co-culture. Data is mean +/- S.E. of 5 different subjects. G. Dot plots depict the T cell proliferation in PL- T (act) coculture as measured by CFSE dye dilution. Prol index is proliferation index. Figure is representative of 4 such experiments. 


\section{DISCUSSION}

Here we demonstrate that C-type lectin receptor; CLEC-2 induces Tregs in soluble form as well as when expressed on DCs and platelets.

CLEC-2 belongs to the family of C-type lectin receptors (CLRs) which are a large family of carbohydrate binding, $\mathrm{Ca}^{++}$dependent receptors present on numerous cells types [28]. CLEC-2 is a member of the "dectin-1 cluster" of CLRs and was originally thought to be restricted to platelets. Recent studies document the expression of the receptors in the 'Dectin-1 cluster' on myeloid populations where they function in homeostasis and immunity [2832]. Initial studies suggested that surface expression of CLEC-2 is restricted to platelets, although RT-PCR analysis has shown transcripts in $\mathrm{PBMC}$, bone marrow cells, monocytes, dendritic cells and granulocytes [25, 33]. However, recent studies have reported the expression of CLEC-2 on DCs in inflammatory conditions [34, 35] where based on our observations, CLEC-2 may have a role in suppressing inflammation.

Podoplanin, a sialoglycoprotein is the physiological ligand for CLEC-2 [23, 25]. It is expressed on numerous cell types including mesothelial cells, epithelial cells, fibroblasts, follicular dendritic cells and various tumor cells. In tumors, podoplanin is involved in tumor cellinduced platelet aggregation and tumor metastasis [36]. Podoplanin is also expressed at high levels on the endothelial cells and fibroblastic reticular cells of lymph nodes where it plays a major in maintaining the high endothelial venule integrity during immune response via its binding with CLEC-2 on platelets[37]. Podoplanin-
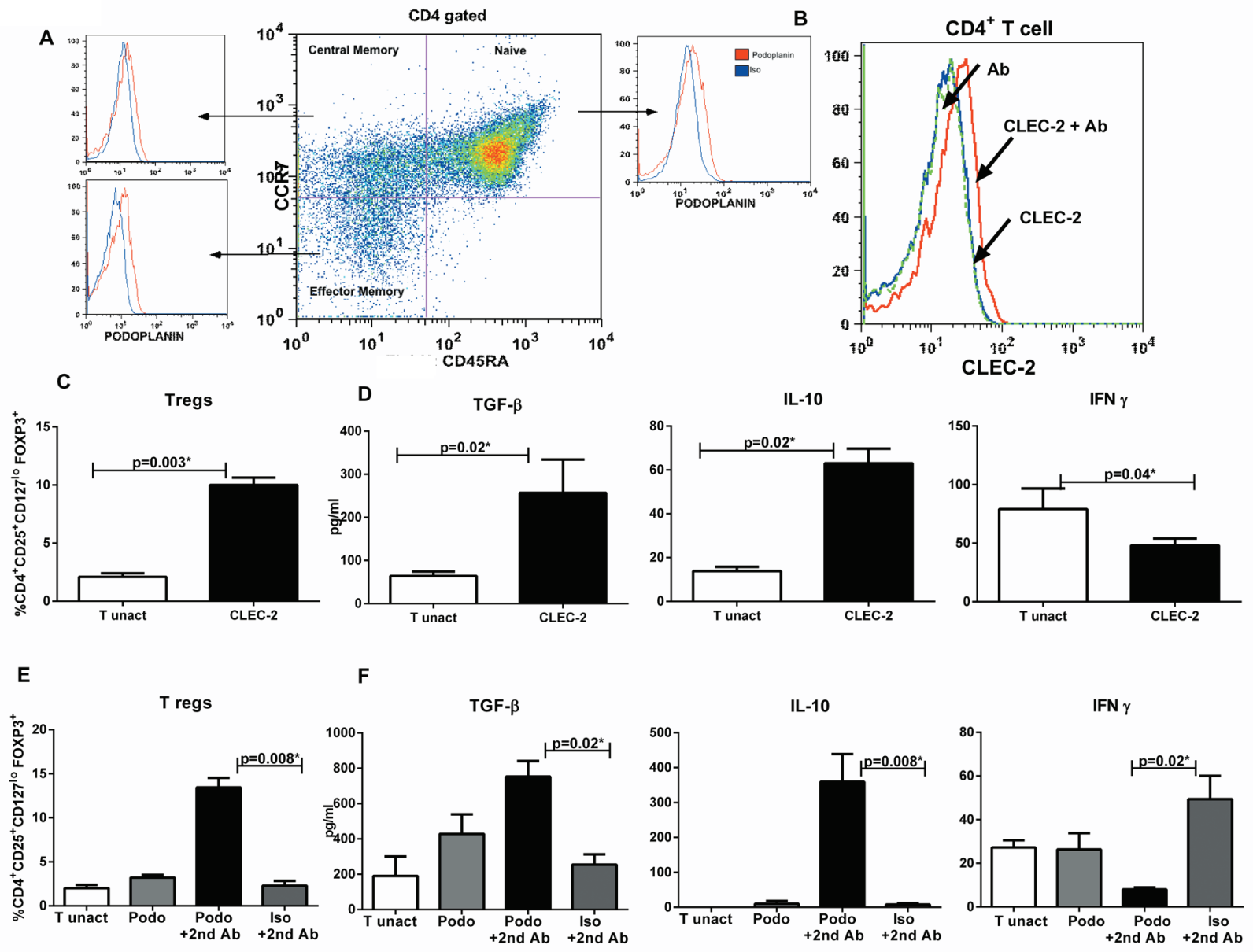

Figure 6: Addition of CLEC-2 protein/podoplanin antibody to T cells induces T regulatory cells. A. Histograms depict the expression of Podoplanin of on naïve, central memory and effector memory CD4 T cells. Figure is representative of 3 such experiments. B. Histogram depicts the binding of CLEC-2 protein on freshly isolated CD4 T cells. Figure is representative of 3 such experiments. Purified T cells were cultured with CLEC-2 protein for $96 \mathrm{~h}$. C. Bar graph depicts the percentage of FoxP3 $3^{+}$cells in gated $\mathrm{CD} 4{ }^{+} \mathrm{CD} 25^{+} \mathrm{CD} 127^{10} \mathrm{FoxP} 3^{+}$ cells in CD4+T cells cultured with CLEC-2. D. Bar graphs depict the production of TGF- $\beta$, IL-10 and IFN- $\gamma$ by T cells cultured in the presence of CLEC-2 protein. Data is mean +/- S.E. of 4 different subjects. Purified T cells were cultured with either podoplanin antibod (podo) or podo $+2^{\text {nd }}$ antibody or isotype antibody (iso) $+2^{\text {nd }}$ antibody for $96 \mathrm{~h}$. C. Bar graph depicts the percentage of FoxP $3^{+}$cells in gated $\mathrm{CD} 4{ }^{+} \mathrm{CD} 25^{+} \mathrm{CD} 127^{\mathrm{lo}} \mathrm{FoxP} 3^{+}$cells. D. Bar graphs depict the production of TGF- $\beta$, IL- 10 and IFN- $\gamma$ by T cells. Data is mean $+/-\mathrm{S}$.E. of 4 different subjects. 
CLEC-2 axis also controls the expansion and contraction of lymph nodes during an immune response $[30,38]$. CLEC-2 expression on DCs and its interaction with podoplanin in fibroblastic reticular cells was also found to be essential for migration of DCs to lymphatics and trafficking within lymph nodes [29]. All these studies have studied the interaction of CLEC-2 on DCs with podoplanin on fibroblast reticular cells. There is a key gap in knowledge about the effect of CLEC-2 expressing DCs on T cells. Peters et al [27] recently demonstrated that podoplanin is expressed on effector T cells during autoimmune inflammation where it functions as an inhibitory molecule promoting tolerance. Our results also demonstrate that CLEC-2 binds to $\mathrm{T}$ cells (Figure 6B) and ligation of podoplanin on $\mathrm{T}$ cells induces $\mathrm{T}$ reg cells (Figure 6E-6F). Therefore, CLEC-2 may be inducing Tregs via engagement of podoplanin on T cells.

Our discovery that PDGF can induce regulatory DCs identifies novel approaches to generate regulatory or tolerogenic DCs. Furthermore, our finding that CLEC-2 protein by itself and podoplanin antibody are capable of inducing $\mathrm{T}$ regs identifies novel approaches for induction of Tregs for immunotherapy against transplantation and autoimmunity. Local infusion of CLEC-2 or podoplanin antibody in autoimmune diseases such as Multiple Sclerosis, rheumatoid arthritis may prove useful in suppressing inflammation. This is supported by the fact that global deletion of podoplanin in mice resulted in enhanced $\mathrm{T}$ cell responses as well as spontaneous development of EAE [27]. Furthermore, podoplanin expressed on Th17 cells in mice $[27,39,40]$ inhibits the long-term Th17 responses in the target organ by reducing sensitivity to IL-7 survival signals, thereby preventing tissue damage.

Our results also suggest a novel mechanism by which platelets may be inducing immune suppression and promoting tumor growth. The activation of platelets releases PDGF which not only causes platelet aggregation and angiogenesis but also induces tolerance in DCs via induction of CLEC-2. PDGF is also known to upregulate the expression of CLEC-2 on platelets. Both these cells together enhance the induction of Tregs in the tumor microenvironment. Our observations suggest novel targets for treatment of tumors. Inhibitors of CLEC-2 which prevent the binding of of CLEC-2 with podoplanin on T cells may prove useful in reducing immunosuppression in tumor microenvironment. However, such therapies would require careful design so that the effect is specific to tumors and does not induce other physiological interactions of CLEC-2. In this regard, Kato et al have recently reported the development of a podoplanin antibody which specifically recognizes podoplanin on tumor cells and not on endothelial cells [41].

To our knowledge this the first report of CLEC-2 expression of DCs and its binding with podoplanin on $\mathrm{T}$ cells in humans. As mentioned, this knowledge has the potential to lead to the development of novel therapies against tumors and autoimmunity.

\section{MATERIALS AND METHODS}

\section{Blood donors}

Blood samples were obtained from healthy volunteers via Institute for Clinical and Translational Science (ICTS), UC Irvine. This study was approved by the Institutional Review Board of the University of California (Irvine, CA).

\section{Culture and stimulation of human monocyte- derived DCs}

Monocyte derived DCs were prepared as described before by culturing the purified monocytes with GMCSF and IL-4. DCs (CD14-HLA-DR ${ }^{+} \mathrm{CD} 11 \mathrm{c}^{+}$cells) were collected after 6 days [32]. Serum free, AIM V media was used for culture. The purity of the DCs was $>95 \%$ as determined by the expression of CD14, CD11c and HLADR. DCs collected were stimulated with recombinant PDGF-AB (Peprotech, NJ) at a concentration ranging from $1-100 \mathrm{ng} / \mathrm{ml}$. $48 \mathrm{~h}$ later supernatant was collected and stored at $-70^{\circ} \mathrm{C}$ until analyzed. In experiments with PAM, DCs were treated with PDGF for 24h and subsequently stimulated overnight with PAM 3 Cys (Invivogen) at a concentration of $10 \mu \mathrm{g} / \mathrm{ml}$. Cytokines, IL-6, IL-10, TNF- $\alpha$, CXCL-8, MCP-1, CXCL-10 in the supernatants was measured by multiplex cytokine assay (eBiosciences, CA) as per the manufacturer's protocol.

Control and PDGF-stimulated DCs (PDGFDC) were analyzed for the expression of CD40, CD80, CD86, CD83, PDL-1, B7DC, B7Rh and HLADR (BD Bioscience) using Flow jo (Treestar Inc).

\section{Allogeneic DC-T cell co-cultures}

PDGF-stimulated and unstimulated DCs were cultured with magnetic bead purified (StemCell, Vancouver, Canada), allogeneic $\mathrm{T}$ cells at a ratio of $1: 10$. After 6 days of incubation, the supernatant was collected and the secretion of TGF- $\beta$, IL- 5 , IL- 4 , IFN- $\gamma$, IL-10, (BD Bioscience) was assessed using ELISA. Subsequently, the cells were collected and stained with antibodies for CD4, CD25, CD127 and FoxP3 to stain for Tregs. $\mathrm{CD} 4{ }^{+} \mathrm{CD} 25^{+} \mathrm{CD} 127^{\text {lo }}$ gated cells were analyzed for the expression of FoxP3. In some assays to measure proliferation, $T$ cells were labeled with CFSE and proliferation was measured by flow cytometry as described [42]. 


\section{Genearray of DCs}

DCs and PDGF-DCs were generated as described above. RNA was extracted from DC and corresponding PDGF-DC from 3 different subjects using TRI reagent as in the past [43]. Affymetrix gene array (Human gene 1.0ST array) was performed by UCI genomics high throughput facility as per the manufacturer's instructions. Genearray data was analyzed by Genesifter.

\section{CLEC-2 transfection and staining}

CLEC-2 plasmid was a kind gift from Dr. Steve Watson U.K[24]. CLEC-2 was transfected into immature DCs using CombiMag Magnetofection (Chemicell, Berlin, Germany) kit as per the manufacturer's instructions. Magnetofection ${ }^{\mathrm{TM}}$ is a novel, simple and highly efficient method to transfect cells in culture. It exploits magnetic force exerted upon gene vectors associated with magnetic particles to draw the vectors into the target cells. In this manner, the full vector dose applied gets concentrated on the cells within a few minutes so that $100 \%$ of the cells get in contact with a significant vector dose. Briefly, immature DCs were derived from monocytes. $5 \times 10^{5}$ DCs were added/ well of a 24 well plate. Non-adherent cell protocol for CombiMag was used. Transfection reagent was Roche XtremeGENE.

Expression of CLEC-2 was determined $48 \mathrm{~h}$ after transfection using specific antibody ( $\mathrm{RnD}$ systems) followed by FITC conjugated second antibody.

\section{Platelet and $\mathbf{T}$ cell co-cultures}

Platelets were purified from whole blood using the protocol described [44]. Briefly blood was centrifuged at $200 \mathrm{x} \mathrm{g}$ or $15 \mathrm{~min}$ at room temperature to obtain plateletrich plasma. To obtain a platelet pellet, the collected plasma was centrifuged at $250 \mathrm{x}$ g for $5 \mathrm{~min}$ at RT. The pellet was suspended in AIM V. T cells were purified from the same donor using magnetic beads as described above. Platelets and $\mathrm{T}$ cells were cultured at ratios ranging from 1:1 to $1: 5$ for $72 \mathrm{~h}$. Subsequently, the cells were collected and stained for CD4, CD25, CD127 and FoxP3 to stain for $\mathrm{T}$ regulatory cells as for DCs. The supernatant was collected was assayed for TGF- $\beta$, IFN- $\gamma$, IL-10 by ELISA.

Experiments were also performed where platelets were cultured with activated T cells. anti-CD3 and antiCD28 coated Dynabeads (Invitrogen, CA) were used for T cell activation [45]. For proliferation measurements CFSE labeled $\mathrm{T}$ cells were used.

\section{Podoplanin staining on CD4 T cells}

PBMCs were stained with CD4, CD45RA and CCR7 antibodies to identify naïve $\left(\mathrm{CD} 4{ }^{+} \mathrm{CD} 45 \mathrm{RA}^{+} \mathrm{CCR} 7^{+}\right)$, central memory $\left(\mathrm{CD} 4^{+} \mathrm{CD} 45 \mathrm{RA}-\mathrm{CCR} 7^{+}\right)$and effector memory $\left(\mathrm{CD}^{+}{ }^{+} \mathrm{CD} 45 \mathrm{RA}{ }^{-C C R} 7^{-}\right)$subsets. Podoplanin was stained using a specific antibody from Biolegend, San Diego, CA.

\section{T reg induction by recombinant CLEC-2 protein and podoplanin crosslinking}

Purified $\mathrm{T}$ cells (unactivated and activated as described above were cultured with recombinant CLEC2 protein ( $\mathrm{RnD}$ systems) at $1 \mu \mathrm{g} / \mathrm{ml}$ for $96 \mathrm{~h}$. T cells were stained for $\mathrm{T}$ regs as described. Supernatants collected were assayed for IL-10, IFN- $\gamma$ and TGF- $\beta$.

Purified T cells were cultured with Podoplanin antibody $(1 \mu \mathrm{g} / \mathrm{ml})$ or isotype control for $1 \mathrm{~h}$ and subsequently crosslinked with secondary anti-rat antibody. 96h later T cells were stained for $\mathrm{T}$ regs as described. Supernatants collected were assayed for IL-10, IFN- $\gamma$ and TGF- $\beta$.

\section{Statistical analysis}

Statistical analysis was performed using Graph Pad Prism. Within group differences between unstimulated and stimulated conditions were tested using paired t-tests. Values of $p<0.05$ were considered significant.

\section{ACKNOWLEDGMENTS}

We are grateful to Dr. Steve Watson for providing the CLEC-2 plasmid and ICTS for the blood. The project described was supported by AG045216 to AA and National Center for Research Resources and the National Center for Advancing Translational Sciences, National Institutes of Health, through Grant UL1 TR000153. The content is solely the responsibility of the authors and does not necessarily represent the official views of the NIH.

\section{CONFLICTS OF INTEREST}

The authors declare no conflict of interest.

\section{Author contributions}

SA performed experiments and analyzed data for all figs. SG performed experiments for Figures $5 \& 6$. P. H. helped SA in some experiments. J.C. analyzed the microarray data. AA performed experiments, wrote the manuscript and supervised the experiments. 


\section{REFERENCES}

1. Holmdahl R, Malmstrom V and Burkhardt H. Autoimmune priming, tissue attack and chronic inflammation - the three stages of rheumatoid arthritis. European journal of immunology. 2014; 44:1593-1599.

2. Buckner JH. Mechanisms of impaired regulation by $\mathrm{CD} 4(+) \mathrm{CD} 25(+) \mathrm{FOXP3}(+)$ regulatory $\mathrm{T}$ cells in human autoimmune diseases. Nature reviews Immunology. 2010; $10: 849-859$.

3. Fujio K, Okamura T, Sumitomo S and Yamamoto K. Regulatory T cell-mediated control of autoantibody-induced inflammation. Frontiers in immunology. 2012; 3:28.

4. Smigiel KS, Srivastava S, Stolley JM and Campbell DJ. Regulatory T-cell homeostasis: steady-state maintenance and modulation during inflammation. Immunological reviews. 2014; 259:40-59.

5. Chong AS and Alegre ML. Transplantation tolerance and its outcome during infections and inflammation. Immunological reviews. 2014; 258:80-101.

6. Steinman RM. Some active areas of DC research and their medical potential. European journal of immunology. 2010; 40:2085-2088.

7. Thomson AW and Robbins PD. Tolerogenic dendritic cells for autoimmune disease and transplantation. Annals of the rheumatic diseases. 2008; 67 Suppl 3:iii90-96.

8. Torres-Aguilar H, Blank M, Jara LJ and Shoenfeld Y. Tolerogenic dendritic cells in autoimmune diseases: crucial players in induction and prevention of autoimmunity. Autoimmunity reviews. 2010; 10:8-17.

9. Hilkens CM, Isaacs JD and Thomson AW. Development of dendritic cell-based immunotherapy for autoimmunity. International reviews of immunology. 2010; 29:156-183.

10. Steinbrink K, Graulich E, Kubsch S, Knop J and Enk AH. CD4(+) and CD8(+) anergic T cells induced by interleukin10-treated human dendritic cells display antigen-specific suppressor activity. Blood. 2002; 99:2468-2476.

11. Trabanelli S, Ocadlikova D, Evangelisti C, Parisi S and Curti A. Induction of regulatory $\mathrm{T}$ Cells by dendritic cells through indoleamine 2,3-dioxygenase: a potent mechanism of acquired peripheral tolerance. Current medicinal chemistry. 2011; 18:2234-2239.

12. Maldonado RA and von Andrian UH. How tolerogenic dendritic cells induce regulatory $\mathrm{T}$ cells. Advances in immunology. 2010; 108:111-165.

13. Martin E, Capini C, Duggan E, Lutzky VP, Stumbles P, Pettit AR, O'Sullivan B and Thomas R. Antigen-specific suppression of established arthritis in mice by dendritic cells deficient in NF-kappaB. Arthritis and rheumatism. 2007; 56:2255-2266.

14. Bambace NM and Holmes CE. The platelet contribution to cancer progression. Journal of thrombosis and haemostasis : 2011; 9:237-249.

15. Sierko E and Wojtukiewicz MZ. Platelets and angiogenesis in malignancy. Seminars in thrombosis and hemostasis. 2004; 30:95-108.

16. Fujita $\mathrm{N}$ and Takagi $\mathrm{S}$. The impact of Aggrus/podoplanin on platelet aggregation and tumour metastasis. Journal of biochemistry. 2012; 152:407-413.

17. Tsirakis G, Pappa CA, Kanellou P, Stratinaki MA, Xekalou A, Psarakis FE, Sakellaris G, Alegakis A, Stathopoulos $\mathrm{EN}$ and Alexandrakis MG. Role of platelet-derived growth factor- $\mathrm{AB}$ in tumour growth and angiogenesis in relation with other angiogenic cytokines in multiple myeloma. Hematological oncology. 2012; 30:131-136.

18. Jain RK and Booth MF. What brings pericytes to tumor vessels? The Journal of clinical investigation. 2003; 112:1134-1136.

19. Liu X, Ciumas C, Huang YM, Steffensen KR, Lian H, Link $\mathrm{H}$ and Xiao BG. Autoantigen-pulsed dendritic cells constitute a beneficial cytokine and growth factor network in ameliorating experimental allergic encephalomyelitis. Multiple sclerosis. 2005; 11:381-389.

20. Motta JM, Sperandio A, Castelo-Branco MT and Rumjanek VM. Induction of suppressive phenotype in monocytederived dendritic cells by leukemic cell products and IL1beta. Human immunology. 2014; 75:641-649.

21. Travis MA and Sheppard D. TGF-beta activation and function in immunity. Annual review of immunology. 2014; 32:51-82.

22. Demoulin JB and Essaghir A. PDGF receptor signaling networks in normal and cancer cells. Cytokine \& growth factor reviews. 2014; 25:273-283.

23. Suzuki-Inoue $\mathrm{K}$, Inoue $\mathrm{O}$ and Ozaki Y. Novel platelet activation receptor CLEC-2: from discovery to prospects. Journal of thrombosis and haemostasis : 2011; 9 Suppl $1: 44-55$.

24. Fuller GL, Williams JA, Tomlinson MG, Eble JA, Hanna SL, Pohlmann S, Suzuki-Inoue K, Ozaki Y, Watson SP and Pearce AC. The C-type lectin receptors CLEC-2 and Dectin-1, but not DC-SIGN, signal via a novel YXXLdependent signaling cascade. The Journal of biological chemistry. 2007; 282:12397-12409.

25. Suzuki-Inoue K, Fuller GL, Garcia A, Eble JA, Pohlmann S, Inoue O, Gartner TK, Hughan SC, Pearce AC, Laing GD, Theakston RD, Schweighoffer E, Zitzmann N, Morita T, Tybulewicz VL, Ozaki Y, et al. A novel Syk-dependent mechanism of platelet activation by the C-type lectin receptor CLEC-2. Blood. 2006; 107:542-549.

26. Nagae M, Morita-Matsumoto K, Kato M, Kaneko MK, Kato Y and Yamaguchi Y. A platform of C-type lectin-like receptor CLEC-2 for binding O-glycosylated podoplanin and nonglycosylated rhodocytin. Structure. 2014; 22:17111721.

27. Peters A, Burkett PR, Sobel RA, Buckley CD, Watson SP, Bettelli E and Kuchroo VK. Podoplanin negatively regulates CD4+ effector $\mathrm{T}$ cell responses. The Journal of clinical investigation. 2015; 125:129-140. 
28. Pyz E, Marshall AS, Gordon S and Brown GD. C-type lectin-like receptors on myeloid cells. Annals of medicine. 2006; 38:242-251.

29. Acton SE, Astarita JL, Malhotra D, Lukacs-Kornek V, Franz B, Hess PR, Jakus Z, Kuligowski M, Fletcher AL, Elpek KG, Bellemare-Pelletier A, Sceats L, Reynoso ED, Gonzalez SF, Graham DB, Chang J, et al. Podoplaninrich stromal networks induce dendritic cell motility via activation of the C-type lectin receptor CLEC-2. Immunity. 2012; 37:276-289.

30. Astarita JL, Cremasco V, Fu J, Darnell MC, Peck JR, Nieves-Bonilla JM, Song K, Kondo Y, Woodruff MC, Gogineni A, Onder L, Ludewig B, Weimer RM, Carroll MC, Mooney DJ, Xia L, et al. The CLEC-2-podoplanin axis controls the contractility of fibroblastic reticular cells and lymph node microarchitecture. Nature immunology. 2015; 16:75-84.

31. Sobanov Y, Bernreiter A, Derdak S, Mechtcheriakova D, Schweighofer B, Duchler M, Kalthoff F and Hofer E. A novel cluster of lectin-like receptor genes expressed in monocytic, dendritic and endothelial cells maps close to the NK receptor genes in the human NK gene complex. European journal of immunology. 2001; 31:3493-3503.

32. Agrawal S, Gupta S and Agrawal A. Human dendritic cells activated via dectin-1 are efficient at priming Th17, cytotoxic CD8 T and B cell responses. PloS one. 2010; 5:e13418.

33. Colonna M, Samaridis J and Angman L. Molecular characterization of two novel C-type lectin-like receptors, one of which is selectively expressed in human dendritic cells. European journal of immunology. 2000; 30:697-704.

34. Mourao-Sa D, Robinson MJ, Zelenay S, Sancho D, Chakravarty P, Larsen R, Plantinga M, Van Rooijen N, Soares MP, Lambrecht B and Reis e Sousa C. CLEC2 signaling via Syk in myeloid cells can regulate inflammatory responses. European journal of immunology. 2011; 41:3040-3053.

35. Lowe KL, Navarro-Nunez L, Benezech C, Nayar S, Kingston BL, Nieswandt B, Barone F, Watson SP, Buckley $\mathrm{CD}$ and Desanti GE. The expression of mouse CLEC-2 on leucocyte subsets varies according to their anatomical location and inflammatory state. European journal of immunology. 2015 ;45(9):2484-93.

36. Hoshino A, Ishii G, Ito T, Aoyagi K, Ohtaki Y, Nagai K, Sasaki H and Ochiai A. Podoplanin-positive fibroblasts enhance lung adenocarcinoma tumor formation: podoplanin in fibroblast functions for tumor progression. Cancer research. 2011; 71:4769-4779.

37. Herzog BH, Fu J, Wilson SJ, Hess PR, Sen A, McDaniel JM, Pan Y, Sheng M, Yago T, Silasi-Mansat R, McGee S, May F, Nieswandt B, Morris AJ, Lupu F, Coughlin $\mathrm{SR}$, et al. Podoplanin maintains high endothelial venule integrity by interacting with platelet CLEC-2. Nature. 2013; 502:105-109.

38. Acton SE, Farrugia AJ, Astarita JL, Mourao-Sa D, Jenkins
RP, Nye E, Hooper S, van Blijswijk J, Rogers NC, Snelgrove KJ, Rosewell I, Moita LF, Stamp G, Turley SJ, Sahai E and Reis e Sousa C. Dendritic cells control fibroblastic reticular network tension and lymph node expansion. Nature. 2014; 514:498-502.

39. Miyamoto Y, Uga H, Tanaka S, Kadowaki M, Ikeda M, Saegusa J, Morinobu A, Kumagai S and Kurata H. Podoplanin is an inflammatory protein upregulated in Th17 cells in SKG arthritic joints. Molecular immunology. 2013; 54:199-207.

40. Peters A, Pitcher LA, Sullivan JM, Mitsdoerffer M, Acton SE, Franz B, Wucherpfennig K, Turley S, Carroll MC, Sobel RA, Bettelli E and Kuchroo VK. Th17 cells induce ectopic lymphoid follicles in central nervous system tissue inflammation. Immunity. 2011; 35:986-996.

41. Kato Y and Kaneko MK. A cancer-specific monoclonal antibody recognizes the aberrantly glycosylated podoplanin. Scientific reports. 2014; 4:5924.

42. Sridharan A, Esposo M, Kaushal K, Tay J, Osann K, Agrawal S, Gupta S and Agrawal A. Age-associated impaired plasmacytoid dendritic cell functions lead to decreased CD4 and CD8 T cell immunity. Age. 2011; 33:363-376.

43. Agrawal A, Agrawal S, Cao JN, Su H, Osann K and Gupta S. Altered innate immune functioning of dendritic cells in elderly humans: a role of phosphoinositide 3-kinasesignaling pathway. Journal of immunology. 2007; 178:6912-6922.

44. Kramer PA, Chacko BK, Ravi S, Johnson MS, Mitchell T and Darley-Usmar VM. Bioenergetics and the oxidative burst: protocols for the isolation and evaluation of human leukocytes and platelets. Journal of visualized experiments : 2014;

45. Agrawal A, Su H, Chen J, Osann K, Agrawal S and Gupta $\mathrm{S}$. Increased IL-21 secretion by aged $\mathrm{CD} 4+\mathrm{T}$ cells is associated with prolonged STAT-4 activation and CMV seropositivity. Aging (Albany NY). 2012; 4:648-659. 